\title{
Risk attitude, investments, and the taste for luxuries versus necessities
}

\author{
Jonathan Baron* \\ Department of Psychology, University of Pennsylvania, Philadelphia, PA, USA \\ ${ }^{*}$ Correspondence: baron@psych.upenn.edu
}

\section{INTRODUCTION}

Individuals should differ in their tolerance for risky financial investments. For one thing, people face different income streams. A freelance writer typically faces considerable variability in income, and long-term unpredictability. These should generally be compensated by less risky investment. But a tenured professor faces little variability or unpredictability and can thus afford to take more risks elsewhere, other things being equal. For another thing, people have different tastes for expenditures. Some people value the "finer things" that money can buy, while others are convinced that the best things in life are free.

Individual differences in the taste for luxury should thus affect the utility function for money, e.g., income in retirement. Such differences can provide a test of methods for assessing the utility function. Those with no particular interest in luxuries should have a concave utility function: a reasonable amount of money is sufficient and much more will not improve life that much. Those with more interest in luxuries should have utility functions closer to linear. The former should be more risk averse in investing, other things being equal, in line with expected-utility theory.

I have argued that we should think of utility as something real in the sense in which time and longitude are real, i.e., a measure based on a conception that we superimpose on the world (Baron, 2008), yet the same thing regardless of how we measure it. Utility is not just the output of a black box, such as the answer that subjects give to questions about hypothetical monetary gambles. Such answers could be wrong, just as sundials are wrong about time and bad chronometers lead to errors in assessing longitude. Yet, investment advisors often use hypothetical gambles to provide advice about saving for retirement.

Measures of risk attitude based on gambles are influenced by many other factors aside from the utility of money
(Schoemaker, 1993; Baron, 2008). For example, decisions about risks are affected by: general beliefs about risk taking as a character trait, such as a desire to avoid being foolhardy, or timid; personality traits such as impulsiveness, anxiety level, and sensation-seeking; social pressures connected with these beliefs; superstition; anticipation of emotional reactions to losses, such as regret, guilt feelings (if others are affected), and disappointment, which go beyond the financial consequences in terms of lost purchasing power; lack of understanding of comparative risks and benefits, or the risk/benefit trade-off; misperceptions of probability, such as neglect or exaggeration of very low probabilities; and isolation of individual decisions, so that they are not seen in the context of a total portfolio of income streams from various sources. Moreover, hypothetical gambles provide results that are internally inconsistent (Baron, 1997). More direct measures of utility, such as those based on comparison of differences, may be more valid, and they are at least as justifiable on theoretical grounds (Krantz et al., 1971; Baron, 2008, Chapter 4).

I report a small study suggesting that difference-based measures are more sensitive than gamble-based measures to the taste for luxuries. My approach was to ask people to evaluate a sample of possible expenditures, which I then place, post hoc, along a continuum from necessities to luxuries.

\section{METHOD}

Subjects were 77 members of a panel who did studies on the World Wide Web for pay. (Four others were omitted because they did the study too quickly to have read carefully.) Ages ranged from 20 to 76 (median 44); $36 \%$ were male.

The study began with 36 pages about expenditures after retirement (defined as no longer working or reaching age 65 , whichever came last). Examples of the expenditures were: owning one inexpensive car (versus no car); owning a second inexpensive car (versus one inexpensive car);

owning two top-of-the line cars (versus two inexpensive cars);

having an extra bedroom in your home, for visitors;

having an extra two bedrooms in your home, for visitors, as opposed to one;

flying to see relatives (including children) or friends once a year;

flying to see relatives (including children) or friends five times per year (as opposed to once);

hiring someone to clean your home once per week;

hiring someone to maintain a garden or lawn;

hiring a chauffeur or cook;

being able to hire a personal assistant or nurse if you need assistance for health reasons;

being able to buy appropriate presents for friends and relatives on holidays, birthdays, etc.;

donating $\$ 1,000$ to charity each year (as opposed to less than $\$ 100$ );

donating $\$ 10,000$ to charity each year (as opposed to $\$ 1,000$ ).

The order was fixed but reversed for half the subjects. Order had no effect on any measures of interest and is ignored. (And likewise for the order of question types described later.) After each item, the subject answered the following:

How does this affect what is important to you about your life as a retiree or senior?

* I don't care about this at all.

* This would be nice, but it would have little effect.

* This would have a noticeable effect.

* This would have a large effect.

* This is absolutely essential. 
The last 20 items consisted of 10 items about direct utility measurement and 10 about risk. Five of the utility items were of this form:

Which would have a greater effect on what is important to you about your life as a retiree or senior?

* The difference between a household annual (pre-tax) income of $\$ 40,000$ and $[\$ 50,000, \$ 60,000, \$ 70,000, \$ 80,000$, $\$ 90,000]$, or

* The difference between [\$50,000, $\$ 60,000, \$ 70,000, \$ 80,000, \$ 90,000$ ] and $\$ 120,000$.

The figures in brackets were for the intermediate value, which increased from $\$ 50,000$ to $\$ 90,000$ over the five pages (or decreased, for half the subjects). Then the sequence was repeated, again with $\$ 40,000$ as the lowest income, but with all other differences from $\$ 40,000$ multiplied by 3 , so that the steps were in increments of $\$ 30,000$ instead of $\$ 10,000$ and the top income was $\$ 280,000$ instead of $\$ 120,000$. (Order of the two sequences was reversed for half the subjects.)

The other 10 pages (which came first for half the subjects) were of the form:

Supposed you had a choice of two investments for retirement. Each would provide your sole income during your entire retirement at the given rate (the same for all years). Which would you choose?

* This one would pay $[\$ 50,000, \$ 60,000$, $\$ 70,000, \$ 80,000, \$ 90,000]$ per year (in current dollars) throughout your retirement.

* This one has a $50 \%$ chance of paying $\$ 40,000$ per year and a $50 \%$ chance of paying $\$ 120,000$.

The numbers used, and the orders, were the same as for the difference question. Because of this matching, I could directly compare the subject's risk attitude to the prediction of expected-utility theory.

\section{RESULTS AND DISCUSSION}

I calculated three measures for each subject. One, which I call necessity fever, was the slope of the linear regression of the subject's ratings $(0-4)$ of the 36 expenditure items on the mean ratings of all the subjects. A high positive slope indicated that the subject rated items as essential when they received such high ratings from others, and as unnecessary when others gave them low ratings. A low slope indicated a tendency toward smaller differences in ratings between "essential" and "inessential" items (as determined from other subjects' ratings), hence to have higher than average relative utility for the luxury items, which were, presumably, those that most subjects rated as less than essential. A low slope should predict a less concave (more linear) utility function for money.

The other two measures were simply the mean responses to the difference items and the gamble items, where one indicates that the subject accepted the gamble or thought that the difference between the intermediate and high amounts was larger than the difference between the low and intermediate amounts. These means would be 0.7 (between the third and fourth response option) for those who were risk neutral and had linear utility functions (assuming that these subjects would be indifferent when the intermediate value was equidistant from the high and low values, so that they would respond randomly). Numbers lower than 0.7 indicated risk aversion or concave utility.

The means were 0.22 for the gambles and 0.42 for the difference measures. Subjects were generally risk averse and had concave utility functions. The difference between gambles and difference measures was significant, which indicates that risk aversion cannot be explained entirely in terms of the utility function as measured by difference judgments. Indeed, the two means were uncorrelated across subjects $(r=0.11$, $p=0.34)$.

Of greatest interest were the correlations of these two measures with the necessity-fever measure. As hypothesized, the correlation between slope, the necessity-fever measure, and the difference measure was negative and significant $(r=-0.41, p=0.0002)$. However, the correlation between necessity fever and the gamble measure was essentially zero ( $r=0.05$, slightly in the wrong direction). It is unlikely that this result is due to the unreliability of the gamble measure itself, as the 10 items had a reliability $(\alpha)$ of 0.88 . Moreover, the two dependent correlations $(0.05$ and -0.41$)$ were significantly different $(p=0.0008)$.
The variance of the risk measure was lower than that of the difference measure ( 0.062 versus $0.118, p=0.0060$ for the difference, $p_{\text {rep }}=0.96$ ). This result implies that people differ more in their utility functions than what we would assume from their risk preferences.

Several other studies attempted to replicate this result. One did so successfully with students. But another, also with students, failed to find a significant effect when the utility measures (gamble and difference) came before the luxury measures. Although I made no direct comparison of studies, it is possible that the luxury measures are helpful in thinking about the utility of money in retirement, thus benefiting the difference measure but not the gamble measure, which may still focus people on the risk itself.

\section{CONCLUSION}

Asking people about risk preferences using hypothetical gambles may lead to choices that fail to maximize their expected utility. In particular, some people may have substantial utility for luxuries, so that they ought to be willing to take risks in hopes of being able to afford those luxuries. Others have no use for luxuries and have no conflict with the single goal of trying to insure a no-frills retirement. These two extreme types do not seem to be differentiated by their risk attitude as assessed from hypothetical gambles. But, if we ask them about their utility for money using a method of comparing differences, the results do reflect their different tastes. The use of direct questions about utility could lead to financial advice. For example, a risk lover with no interest in luxuries might be told, "Why take risks? What are you going to do if you make a lot of money? Do you care that much?" Of course, risk itself has consequences for utility in terms of anxiety, regret, and disappointment over the long term, so these factors should be considered too.

More generally, the present results cast doubt on the use of hypothetical gambles to measure utility functions, and they suggest that the use of a simplified measure based comparison of differences is feasible. Researchers often talk about "von Neuman/ Morgenstern utility" as if it were some special sort of thing that is related specifically to gambles. Yet, our interest in utility stems from the idea that it is a measure of goodness, that is, the extent to which our goals 
are achieved. If responses to gambles do not measure utility in this sense, we have better alternative measures. To define utility in terms of responses to gambles is like defining time in terms of the output of a sundial.

To be sure, it is possible that other measures using hypothetical decisions with probabilistic outcomes could do better than the gambles used here. For example, Kusev et al. (2009) and Jones and Oaksford (2011) found that utility functions differed depending on whether the choices were gambles, precautions, or transactions. It is also possible that the direct judgment method used here has other problems that would render it less useful in other contexts.

The present results might be taken as a sign that utility is unstable, and that, therefore, risk preferences are unstable. Yet another way to look at them is to say that the term "preference" is somewhat ambiguous between "what I choose now" and "what is best for me." Responses to gambles may reflect the former but not the latter.

\section{ACKNOWLEDGMENT}

The work was supported by a grant from the U.S.-Israel Bi-national Science Foundation to J. Baron and I. Ritov.

\section{REFERENCES}

Baron, J. (1997). Biases in the quantitative measurement of values for public decisions. Psychol. Bull. 122, 72-88. Baron, J. (2008). Thinking and Deciding, 4th Edn. New York: Cambridge University Press.

Jones, S., and Oaksford, M. (2011). Transactional problem content in cost discounting: parallel effects for probability and delay. J. Exp. Psychol. Learn. Mem. Cogn. 37, 739-747.
Krantz, D. H., Luce, R. D., Suppes, P., and Tversky, A. (1971). Foundations of Measurement, Vol. 1. New York: Academic Press.

Kusev, P., van Schaik, P., Ayton, P., Dent, J., and Chater, N. (2009). Exaggerated risk: prospect theory and probability weighting in risky choice. J. Exp. Psychol. Learn. Mem. Cogn. 35, 1487-1505.

Schoemaker, P. J. H. (1993). Determinants of risk taking: behavioral and economic views. J. Risk Uncertain 6, 49-73.

Received: 11 July 2011; accepted: 25 October 2011; published online: 15 November 2011.

Citation: Baron J (2011) Risk attitude, investments, and the taste for luxuries versus necessities. Front. Psychology 2:329. doi: 10.3389/fpsyg.2011.00329

This article was submitted to Frontiers in Cognition, a specialty of Frontiers in Psychology.

Copyright ( 12011 Baron. This is an open-access article subject to a non-exclusive license between the authors and Frontiers MediaSA, which permits use, distribution and reproduction in other forums, provided the original authors and source are credited and other Frontiers conditions are complied with. 